\title{
Psychological impact of a country-wide lockdown. Role of personal, behavioral, social, and physical conditions on negative and positive affect and meaning in life
}

\author{
Ernesto Suárez ${ }^{1}$, Gladys Rolo-González ${ }^{1}$, Gabriel Muinos ${ }^{2}$, Cristina Chinea-Montesdeoca ${ }^{1}$, \\ Isabel Duarte-Lores ${ }^{1}$ and Domingo Gil Giménez ${ }^{1}$ \\ Universidad de La Laguna (Spain) ${ }^{1}$ \\ University of Groningen (Netherlands) ${ }^{2}$ \\ Contact email: esuarez@ull.edu.es
}

\begin{abstract}
The spread of COVID-19 became the main public health risk for most countries in 2020 . The Spanish government declared a state of emergency, implemented lockdown measures and imposed severe restrictions on mobility and compulsory home isolation. Given this sudden situation, we tested the levels of risk perception, the psychological impact of isolation conditions and of coping behaviors. A total of 1343 adult residents in Spain participated in the study. We measured with an online questionnaire (a) risk perception; (b) individual, social, and physical conditions of isolation; and (c) a set of coping behaviors. We tested how the conditions of isolation and the individual behavior affected positive and negative affect and meaning in life. We observed that risk perception was directly linked with the individual and social situation of the participants. Personal resilience, employment status, profile of cohabitants, and using open air spaces in the house are linked with the emotional situation of the participants. Additionally, we found that some behaviors were related with positive affect, meaning in life, and negative affect. The psychological impact of a nation-wide lockdown is not universal and there are key factors that moderate this impact. We have identified key personal, behavioral, social, and physical factors that may help policy makers and citizens in critical isolation situations. ${ }^{1}$
\end{abstract}

Keywords: COVID Lockdown, Positive Affect, Negative Affect, Meaning in life, Risk Perception, Behavior

Infection and spread of SARS-CoV-2, better known as COVID-19, has become the main public health risk for most countries in 2020. In addition to the rapid and massive spread of the virus, reaching pandemic levels (WHO, 2020a), as of summer 2020, there is no vaccine to prevent and reduce infection rates. When it comes to controlling the disease, the strategy implemented in most affected countries has involved adopting quarantine, following

${ }^{1}$ Study and Analysis of this research was not preregistered 
recommendations from the World Health Organization (WHO, 2020b). Spain is the European country that, after Italy, has suffered the earliest impact and one of the highest numbers of infections and deaths caused by the COVID-19 pandemic (WHO/Europe, 2020). On March $12^{\text {th }}$ 2020, the Spanish government declared a state of emergency, implemented lockdown measures and, as in most European countries, imposed severe restrictions on mobility and compulsory home isolation for the majority of the population, resulting in approximately 47,000,000 people being confined to their homes.

In order to guarantee basic needs, government intervention expressly identified a series of exceptions to these restrictions on the general population (Real Decreto 463/2020, de 14 de marzo). These included travelling for purchasing food and medication, attending to the elderly, walking pets outdoors or going to health centers for urgent reasons. Likewise, all economic activities were banned, except those covering the basic needs of the population (e.g., security and health services, grocery stores, pharmacies or gas stations, etc.). The initial planned duration of quarantine in Spain was 15 days, until March $26^{\text {th }} 2020$. Despite this, authorities extended the duration of confinement on successive occasions, until May $4^{\text {th }}$. During the initial period of confinement, the number of infections and deaths increased, as well as hospital admissions throughout the country (Instituto de Salud Carlos III, n.d.), until finally stabilizing and progressively decreasing. In all, COVID-19 led to a strict lockdown of over 50 days in Spain, followed by progressive de-escalation measures.

While from a public health perspective, the magnitude of COVID-19 infection and its impact on the health care systems is unprecedented, the strict and massive lockdown of the majority of a country's population for such a prolonged period of time is an absolutely novel social circumstance, with psychological, social, and community implications. 
Previous evidence exists of the psychological impact of quarantines related to various outbreaks such as SARS, Ebola, H1N1 or MERS. In general, people who have been quarantined tend to report symptoms of general psychological distress, as well as emotional disturbance (e.g., emotional exhaustion, irritability, or anger) or even symptoms of post-traumatic stress (Cowling et al., 2010; Green et al., 2018; Liu et al., 2012; Peng et al., 2010).

Most research addressing the psychological impact of quarantines focuses on the analysis of negative effects and risks involved, either during or after. Recent work on COVID-19, involving either the general population, health professionals, or infected patients, is developing in a similar manner (Bo et al., 2020; Cao et al., 2020; Li et al., 2020; Lohiniva et al., 2020; Wang et al., 2020).

Furthermore, risks associated with confinement are not limited exclusively to physical or mental health conditions. Such negative effects are also linked to broad social aspects of daily life, as neighborhood and family relationships, or economic conditions (Ko et al., 2006; Mihashi et al., 2009). In any case, it is important to note that this negative impact is neither widespread nor direct. Factors have been identified that can exacerbate the psychological damage associated with quarantine, such as length of confinement, inadequate supplies and poor environmental conditions, fear of infection, or frustration and boredom (Brooks et al., 2020). Less systematic evidence exists on what may be mitigating such negative effects and what factors may be acting as protectors of psychological well-being. For example, family income stability and living with parents versus living alone were identified as protective factors against anxiety, in Hubei college students, during the COVID-19 outbreak in China (Cao et al., 2020). 
In addition to the existence of factors that moderate the impact of confinement, the consequences of prolonged isolation may emerge with a wide range of expressions. Weber et al. (2019) observed that negative affect was not altered by isolation, in contrast, positive affect tended to decrease as confinement progressed. A similar pattern of emotional response is identified in confinement under extreme environments (e.g., Sandal et al., 2018). Similarly, being confined with others can have paradoxical effects, such as expressing a need to interact with others but with little intimacy, or expecting others to establish close relationships but preferring to maintain little social interaction (Paul et al., 2010). Emotional responses to these situations are therefore not universally negative and can be expressed through a variety of consequences that are not necessarily limited to an increase in negative emotions.

Following guidelines established by the World Health Organization (WHO, 2020b), in order to reduce the risk of developing mental health problems, Fiorillo and Gorwood (2020) note the importance of promoting a series of basic positive coping strategies among the population confined by the COVID-19 pandemic. These include: a) Increasing video communication with friends and family members to proactively break isolation. b) Maintaining regular daily routines, including sleep-wake and diet patterns. c) Developing intellectual, physical, and virtual social activities. d) Focusing on the benefit of confinement both for one's own health and others, by mitigating and finally stopping the pandemic's negative effects. However, maintaining precautionary measures or recommended behaviors may be affected by the severity of the situation or the concern of individuals. For example, in a representative sample of the Italian population, Prati et al. (2011) found that feelings of concern about the 2009 H1N1 influenza pandemic outbreak influenced compliance with protective behaviors recommended by health authorities. 
Literature has identified that positive actions increase positive emotions, alleviate negative ones and satisfy psychological needs like autonomy, purpose, competence or connectedness (e.g., Shin et al., 2018). Similarly, resilience has a positive influence on psychological coherence, subjective well-being, positive emotions, proactive coping behaviors, or cohesive relationships (Moore et al., 2014) and is inversely linked with psychological distress (Lee et al., 2018; Osofsky et al., 2011). As such, psychological resilience can also act as a protective factor during strict quarantine.

Therefore, one way to lessen the negative effects of psychological distress could involve analyzing any existing relationships between personal and social conditions during lockdown, affective reactions and psychological well-being. Until an effective and sufficiently distributed vaccine is available, this approach would provide guidelines for identifying successful psychological mitigation strategies, useful in planning future and foreseeable quarantines, in the face of possible seasonal outbreaks of COVID-19.

The aim of this study is to analyze the affective response to compulsory home isolation during the COVID-19 outbreak in Spain. Specifically, to analyze: a) risk perception regarding personal health and economic conditions; b) the impact of others and environmental conditions during home isolation on personal well-being (positive affect, negative affect and meaning in life); c) the influence of psychological resilience and positive coping activities as factors promoting well-being. 


\section{Method}

\section{Participants}

A total of 1407 people participated in this study, of the total sample, 46 were discarded for not residing in Spain and 18 for being underage. The final sample consisted of 1343 people, (31.9\%, men; $66.3 \%$, women; $0.2 \%$ marked the option Other, and $1.6 \%$ did not answer). Participants' average age was 39.66 years $(S D=14.865)$ ranging from 18 to $84.35 .1 \%$ of the participants were under 30 and $3.1 \%$ were older than 65 . Regarding academic level, $23.3 \%$ had completed secondary education, $18.4 \%$ had vocational education or training and $37.1 \%$ had completed university studies.

Table 1 includes details related to participants' housing, a relevant factor given that it was the place where participants were confined to at the moment of answering the survey. An equitable distribution is observed between the different types of housing and the majority claimed to have space to be alone within their homes (91.4\%) and open-air spaces (79.3\%). 
Table 1

Descriptive details of housing conditions

\begin{tabular}{|c|c|c|}
\hline Variables & Frequency & Percentage \\
\hline \multicolumn{3}{|l|}{ Type of housing } \\
\hline Detached house & 320 & 23.8 \\
\hline Townhouse & 198 & 14.7 \\
\hline Building with 6 or less apartments & 245 & 18.2 \\
\hline Building with 6-12 apartments & 209 & 15.6 \\
\hline Building with more than 12 apartments & 269 & 20.0 \\
\hline $\begin{array}{l}\text { Residential complex with a shared } \\
\text { garden or patio }\end{array}$ & 99 & 7.4 \\
\hline Total & 1340 & 99.8 \\
\hline Missing values & 3 & .2 \\
\hline \multicolumn{3}{|l|}{ Availability of space to be alone } \\
\hline Yes & 1228 & 91.4 \\
\hline No & 115 & 8.6 \\
\hline Total & 1343 & 100 \\
\hline \multicolumn{3}{|l|}{ Use of space to be alone } \\
\hline Never & 254 & 18.9 \\
\hline Almost never & 158 & 11.8 \\
\hline Occasionally & 260 & 19.4 \\
\hline Almost every day & 226 & 16.8 \\
\hline Every day & 445 & 33.1 \\
\hline Total & 1343 & 100 \\
\hline \multicolumn{3}{|l|}{ Availability of open-air spaces } \\
\hline Yes & 1065 & 79.3 \\
\hline No & 278 & 20.7 \\
\hline Total & 1343 & 100 \\
\hline \multicolumn{3}{|l|}{ Use of open-air spaces } \\
\hline Never & 299 & 22.3 \\
\hline Almost never & 104 & 7.7 \\
\hline Occasionally & 249 & 18.5 \\
\hline Almost every day & 316 & 23.5 \\
\hline Every day & 375 & 27.9 \\
\hline Total & 1343 & 100 \\
\hline
\end{tabular}

The average number of people with whom participants were living with is $2.44(S D=$ $1.55)$, in most cases they were relatives $(59.1 \%)$ or couples or spouses $(31.7 \%)$. More than half of participants did not reside with minors $(68.7 \%)$ or with adults over the age of $65(85.3 \%)$. 
Among those who did, they mostly lived with one (66.9\%) or two minors (28.7\%). Among

participants that lived with elderly people, most of them did so with one (76.9\%) or two (21.5\%).

Table 2 shows participants belonging to high-risk groups regarding COVID-19.

Table 2

Participants belonging to high risk groups

\begin{tabular}{|c|c|c|}
\hline \multirow{2}{*}{$\begin{array}{c}\text { Variables } \\
\text { Suffers from a chronic disease }\end{array}$} & Frequency & Percentage \\
\hline & & \\
\hline Yes & 162 & 12.1 \\
\hline No & 1181 & 87.9 \\
\hline Total & 1343 & 100 \\
\hline Lives with someone chronically ill & & \\
\hline Yes & 221 & 16.5 \\
\hline No & 1122 & 83.5 \\
\hline Total & 1343 & 100 \\
\hline Cares for someone chronically ill & & \\
\hline Yes & 45 & 3.4 \\
\hline No & 1298 & 96.6 \\
\hline $\begin{array}{ll}\text { Total } \\
\text { Tol }\end{array}$ & 1343 & 100 \\
\hline Cares for someone with special needs & & \\
\hline Yes & 44 & 3.3 \\
\hline No & 1299 & 96.7 \\
\hline Total & 1343 & 100 \\
\hline $\begin{array}{l}\text { Belong to a high-risk group (i.e.: } \\
\text { pregnant, immunosuppressed, cancer...) }\end{array}$ & & \\
\hline Yes & 78 & 5.8 \\
\hline No & 1265 & 94.2 \\
\hline Total & 1343 & 100 \\
\hline Symptoms of coronavirus & & \\
\hline I have experienced symptoms & 91 & 6.8 \\
\hline The people I live with have had symptom & 75 & 5.6 \\
\hline $\begin{array}{l}\text { Both I and the people I live with have had } \\
\text { symptoms }\end{array}$ & 67 & 5.0 \\
\hline $\begin{array}{l}\text { Neither I nor the people I live with have } \\
\text { had any symptoms }\end{array}$ & 1110 & 82.7 \\
\hline Total & 1343 & 100 \\
\hline
\end{tabular}

Prolonged confinement affected the country's work capacity. Therefore, participants' employment status was especially relevant. Half of the sample worked remotely or was involved 
in long distance academic activity from home (50.3\%), $14.7 \%$ were temporarily unemployed or had stopped working as a result of the COVID-19 pandemic, $11 \%$ were unemployed prior to the pandemic, $18.8 \%$ of participants continued working in person and $5.2 \%$ were retired.

We disseminated the questionnaire using a link with a snowball sampling procedure and several routes. We firstly sent an email to university students; in this email we also asked for their collaboration to spread the questionnaire in their own personal social networks, with the same request for dissemination. Additionally, the authors themselves also used their own social networks (specifically, Facebook, Twitter, and Instagram) with the aim of reaching people within different age groups.

\section{Instruments}

In addition to sociodemographic variables, all participants answered a questionnaire that consisted of the following elements.

Connor-Davidson Resilience Scale (10-item CD-RISC) (Connor \& Davidson, 2003), adapted for its use with Spanish population by Notario-Pacheco et al. (2011). The CD-RISC is a brief self-rated assessment to quantify psychological resilience, conceived as the personal qualities that enable people to thrive under adversity. One example of an item is: "Not easily discouraged by failure". Items were rated from 1 (Strongly disagree) to 7 (Strongly agree), the scale presented a mean score of $5.20(S D=.93)$ and an alpha of .89 .

MLM-10 validated by Morgan and Robinson (2013), is a shortened version of the Meaningful Life Measure (Morgan \& Farsides, 2009) which measures the fulfillment of five sources of personal meaning pertaining to a sense of purpose, excitement, accomplishment, 
principles, and value. One example of an item is: "I have a clear idea of what my future goals and aims are". Items were rated from 1 (Strongly disagree) to 7 (Strongly agree), the scale presented a mean score of $5.54(S D=.90)$ and an alpha of .85 .

Positive and Negative Affect Schedule (PANAS) (Watson et al., 1988), in its short 10 item version, adapted for its use with Argentinian population by Flores-Kanter and Medrano (2018). PANAS measures the weekly or general frequency in which people have manifested/felt the emotional states Positive and Negative Affect, from a list of adjectives that describe such moods. Examples of adjectives are: "Inspired" (positive affect) and "Afraid" (Negative Affect). For this study, instructions were adapted and participants were asked to refer to the mood “during the quarantine period". Items were rated from 1 (Little or nothing) to 5 (Extremely). Positive affect presented a mean score of $2.77(S D=.712)$ and an alpha of .68 , and negative affect presented a mean score of $2.26(S D=.798)$ and an alpha of .83 .

Risk perception was measured from the direct assessment of risk severity regarding two dimensions: health and economic conditions. Each dimension was measured at three different levels: personal risk, risk to family and friends, and risk to town/city neighbors and residents. Perceived severity is one of the basic qualitative characteristics of risk, according to the psychometric risk paradigm (e.g. Slovic et al., 1985). The criteria for distinguishing risk severity in terms of aspects and levels, has in turn been taken from studies that apply the psychometric model of risk associated with pandemics (e.g., Aragonés et al., 2010; Han et al., 2014). The scale consisted of 6 items, 3 for health risk perception and 3 for economic risk perception: Coronavirus is a serious risk to my own health/financial situation (depending on the dimension measured), Coronavirus is a serious risk to the health/financial situation of my family and friends, Coronavirus is a serious risk to the health/ financial situation of the residents of my town/city. 
Items were rated from 1 (Strongly disagree) to 7 (Strongly agree). Health risk perception presented a mean score of $5.83(S D=1.13)$ and an alpha of .74 , and economic risk perception presented a mean score of $5.81(S D=1.19)$ and an alpha of .76 .

To measure people's behavior during confinement, we included 13 activities recommended by public health institutions during confinement. These included activities such as physical exercise, working remotely, and caring for neighbors and dependents. These behaviors were selected from documents distributed by Spanish and international health authorities during March (Real Decreto 463/2020, de 14 de marzo; WHO, 2020c). The items were rated from 1 (Never) to 5 (Every day).

Information on housing and its occupants during confinement was collected with 6 items regarding housing characteristics (i.e. housing type, living space and availability of open-air spaces); number of people living together; people with chronic diseases or high-risk groups (e.g. pregnancy or immunosuppression).

\section{Procedure}

At the beginning of the questionnaire, participants were informed about the objectives of the study, the approximate duration of the participation, and the option of refusing to participate. Second, participants were informed that their personal data and information provided during the study would be stored securely, and that it would be processed with confidentiality, in accordance with Spanish data protection regulations. Finally, they were asked for their consent to participate in the survey. The questionnaire was then presented using the Qualtrics data collection platform for response and was collected between the 23rd and $29^{\text {th }}$ of March, during the second week under lockdown in Spain. 
Given that several of the variables that were used consisted of one item, we decided to use non-parametric statistics. Furthermore, to keep consistency across analysis, including statistical assumptions, we decided to use non-parametric statistics for the whole set of data analysis.

\section{Results}

To understand the psychological consequences of household isolation in the context of a nation-wide lockdown, we need to assess at least (a) individuals' risk perceptions, (b) the psychological effects of the conditions of the home isolation, and (c) how engaging in different actions may be linked with positively coping with the situation. To avoid the statistical threat of the family-wise error rate, given that we conducted multiple tests per section, we implemented the Bonferroni correction, accepting an initial $p$-value of .05 that was adapted for the number of tests in each subsection of the reported results.

\section{Differences in risk perception associated with COVID-19 according to sociodemographic profile}

We decided to study two specific types of risk perception that may be key in this context, health risk perception, due to the origins of the lockdown as a health-related issue, and economic risk perception, due to the massive impact on the economic infrastructure caused by lockdown measures.

A significant relationship was found between health and economic risk perceptions, $r_{s}=$ $.56, p<.001$. We tested whether there were differences depending on participants' sociodemographic profile and found that the older the participant, the higher health risk perception is $r_{s}=.19, p<.001$, but no significant correlation was found between age and 
economic risk perception. Participants belonging to high risk groups reported higher health risk perception $(M d n=6.33 ;$ Rank $=737.18)$ than those not belonging to high risk groups $(M d n=$ 6.0; Rank $=642.75), U=165699.50, p<.001, \eta^{2}=.013$. No difference was found in the perception of health or economic risk according to gender. However, we found that health risk perception is statistically different depending on employment status, $\chi^{2}(3)=21.187, p<.001$, $\eta^{2}=.015 ;$ specifically between participants that worked from home $(M d n=6.0 ;$ Rank $=596.45)$ versus workers who had to attend their workplace in person $(M d n=6.0$; $\operatorname{Rank}=681.25)(p=$ $.01)$ and versus workers who were temporarily suspended due to lockdown $(M d n=6.3$; Rank $=$ 714.99) $(p<.001)$. No difference was found among other groups.

As expected, participants' economic risk perception differed depending on their employment status, $\chi^{2}(3)=67.354, p<.001, \eta^{2}=.055$. Specifically, participants unemployed prior to confinement $(M d n=6.0 ;$ Rank $=688.74)$ scored higher in economic risk perception than those still working from home $(M d n=6.0 ;$ Rank $=578.62)(p=.037)$. Additionally, participants temporarily suspended from their job $(M d n=6.7$; Rank $=817.27)$ scored significantly higher than those attending their workplace in person $(M d n=6.0 ;$ Rank $=634.03)(p<.001)$ and those working from home $(M d n=6.0 ;$ Rank $=488.41)(p<.001)$.

Finally, people that had themselves shown symptoms of infection or who lived with someone who had, reported lower levels of health risk perception $(M d n=6.0 ; \operatorname{Rank}=583.53), U$ $=149928.50, p<.001, \eta^{2}=.011$ than people who had not experienced any symptoms $(M d n=$ $6.0 ;$ Rank $=690.57)$. 


\section{Emotional and well-being effects of personal profile, and the social, and environmental characteristics of home isolation}

This section looks at how different personal, social and environmental conditions relate to three key indicators of well-being: negative affect, positive affect, and finding meaning in life. Results show that negative affect tends to be lower with age, $r_{s}=-.09, p<.001$, whereas positive affect, $r_{s}=.12, p<.001$, and meaning in life, $r_{s}=.09, p<.001$, tend to be higher. Women reported higher levels of negative affect $(M d n=2.20$; Rank $=713.88)$ than men $(M d n=2.0$; Rank $=546.43), U=142065.00, p<.001, \eta^{2}=.038$, but no difference was found in positive affect or meaning in life depending on gender.

Significant differences in finding meaning in life were found with regard to employment status, $\chi^{2}(3)=17.933, p<.001, \eta^{2}=.051$. Specifically, participants unemployed prior to confinement $(M d n=5.45 ;$ Rank $=573.32)$ reported finding less meaning in life than participants working in person $(M d n=5.70 ;$ Rank $=638.97)(p=.009)$, participants working at home $(M d n=$ 5.75; Rank $=656.63)(p<.001)$, and participants being temporarily suspended $(M d n=5.70$; Rank $=656.28)(p=.003)$.

No difference was found in positive affect, negative affect or meaning in life based on belonging or not to risk groups. The capacity of an individual to cope and bounce back from a negative situation may be a factor that explains variations found in participants' emotional situation. The higher the individual resilience of a participant, the lower the negative affect, $r_{s}=-$ $.27, p<.001$, the higher the positive affect, $r_{s}=.41, p<.001$, and the greater the meaning in life, $r_{s}=.56, p<.001$. 
Participants that had experienced symptoms either themselves or who lived with someone who had, scored lower in positive affect $(M d n=2.6$; Rank $=596.74)$ than participants who had not experienced any symptoms $(M d n=2.8 ; \operatorname{Rank}=687.80), U=146849.50, p=.001, \eta^{2}=.008$. Additionally, they also scored lower in meaning in life $(M d n=5.5 ;$ Rank $=583.37)$ than participants who had not experienced any symptoms or lived with someone who also had not experienced symptoms $(M d n=5.7 ; \operatorname{Rank}=690.60), U=149965.00, p<.001, \eta^{2}=.011$. No significant differences in negative affect were found between these groups.

Regarding immediate social and environmental surroundings during quarantine, people living with others reported higher negative affect $(M d n=2.20 ;$ Rank $=684.37)$ than people living alone $(M d n=1.80$; Rank $=503.74), U=42066.50, p<.001, \eta^{2}=.014$. However, no differences were found in positive affect or in meaning in life. Additionally, no significant differences were found between people living with or without children, and the same is true for those living with or without people over the age of 65 .

Significant differences were found in positive affect depending on the frequency of use of open-air spaces, $\chi^{2}(3)=21.126, p<.001, \eta^{2}=.014$. Specifically, between participants that use open spaces every day $(M d n=2.8 ;$ Rank $=723.39)$ versus participants that never use them $(M d n=2.6 ;$ Rank $=639.52)(p=.031)$ or that use them occasionally $(M d n=2.6 ;$ Rank $=$ 609.83) $(p<.001)$ as well as differences between using them almost every day versus occasional use $(M d n=2.8 ; \operatorname{Rank}=611.20)(p=<.001)$. 


\section{Emotional and well-being effects of activities and behaviors carried out during home isolation}

In extreme situations such as a nation-wide lockdown, knowing how to act and understanding which actions are linked to a positive, health and psychological impact is key. First, we analyzed activities recommended by the $\mathrm{WHO}$ and found that participants that exercised frequently reported lower levels of negative affect than those who did so less frequently. Furthermore, (a) keeping routines and stable schedules, (b) exercising, (c) making video calls with friends and relatives, and (d) developing creative activities at home were linked with higher levels of positive affect and greater meaning in life. We have included all information regarding these behaviors and their different connections in Table 3.

People that frequently engaged in community activities, reported higher positive affect, and higher meaning in life compared with participants who never or almost never partook in such activities. Similarly, people participating in activities that consisted of helping others, reported higher positive affect than those not participating in such activities.

Participants maintaining online activities, as working from home or studying, experienced greater meaning in life. Likewise, those participating in online creative activities such as creating art and participating in digital cultural activities, experienced more positive affect. However, we found no significant reduction of negative emotions for any of these activities. Additionally, it seems that the frequency in which participants bought goods online did not make a difference regarding their affect. 
Finally, no significant differences were found in affect and meaning in life for exterior activities such as going out to buy food, medication or other basic goods, walking the dog or attending a workplace in person.

Table 3

Difference in affect and meaning in life depending on the frequency of coping behaviors

\begin{tabular}{|c|c|c|c|c|c|c|c|c|c|c|c|c|c|c|c|}
\hline & \multicolumn{5}{|c|}{ Negative affect } & \multicolumn{5}{|c|}{ Positive affect } & \multicolumn{5}{|c|}{ Meaning in life } \\
\hline $\begin{array}{l}\text { WHO } \\
\text { activities }\end{array}$ & Low & High & $\mathbf{U}$ & p & $\eta^{2}$ & Low & High & $\mathbf{U}$ & p & $\eta^{2}$ & Low & High & $\mathbf{U}$ & p & $\eta^{2}$ \\
\hline $\begin{array}{l}\text { Keeping } \\
\text { routines }\end{array}$ & 557.53 & 545.36 & $\begin{array}{c}67983.0 \\
0\end{array}$ & .663 & $<.001$ & 380.86 & 572.82 & $\begin{array}{c}45108.5 \\
0\end{array}$ & $<.001$ & .043 & 384.81 & 572.20 & $\begin{array}{c}45689.0 \\
0\end{array}$ & $<.001$ & .041 \\
\hline Exercising & 507.76 & 435.52 & 8861.00 & $<.001$ & .018 & 397.07 & 514.06 & $\begin{array}{c}78577.5 \\
0\end{array}$ & $<.001$ & .046 & 385.22 & 522.46 & $\begin{array}{c}74005.5 \\
0\end{array}$ & $<.001$ & .063 \\
\hline Video calls & 422.43 & 480.30 & $\begin{array}{c}70593.5 \\
0\end{array}$ & .005 & .009 & 410.09 & 484.34 & $\begin{array}{c}67755.5 \\
0\end{array}$ & $<.001$ & .014 & 383.06 & 493.21 & $\begin{array}{c}61538.5 \\
0\end{array}$ & $<.001$ & .031 \\
\hline $\begin{array}{l}\text { Online } \\
\text { creative } \\
\text { activities }\end{array}$ & 519.73 & 480.54 & $\begin{array}{c}83731.0 \\
0\end{array}$ & .058 & .004 & 360.10 & 534.92 & $\begin{array}{c}58541.0 \\
0\end{array}$ & $<.001$ & .073 & 396.75 & 522.43 & $\begin{array}{c}67666.0 \\
0\end{array}$ & $<.001$ & .037 \\
\hline $\begin{array}{l}\text { Community } \\
\text { actions }\end{array}$ & Low & High & $\mathbf{U}$ & $\mathbf{p}$ & $\eta^{2}$ & Low & High & $\mathbf{U}$ & $\mathbf{p}$ & $\eta^{2}$ & Low & High & $\mathbf{U}$ & $\mathbf{p}$ & $\eta^{2}$ \\
\hline $\begin{array}{l}\text { Community } \\
\text { participation }\end{array}$ & 523.65 & 583.93 & $\begin{array}{c}133071 . \\
50\end{array}$ & .002 & .009 & 507.24 & 604.35 & $\begin{array}{c}123063 . \\
00\end{array}$ & $<.001$ & .023 & 507.08 & 604.55 & $\begin{array}{c}122966 . \\
500\end{array}$ & $<.001$ & .023 \\
\hline $\begin{array}{l}\text { Helping } \\
\text { others }\end{array}$ & 553.10 & 546.53 & $\begin{array}{c}50048.5 \\
0\end{array}$ & .043 & $<.001$ & 541.61 & 660.69 & $\begin{array}{c}39724.5 \\
0\end{array}$ & $<.001$ & .012 & 543.73 & 639.59 & $\begin{array}{c}41855.5 \\
0\end{array}$ & .004 & .008 \\
\hline $\begin{array}{l}\text { Donating } \\
\text { money }\end{array}$ & 533.76 & 479.94 & $\begin{array}{c}11673.5 \\
0\end{array}$ & .385 & .001 & 530.37 & 620.90 & $\begin{array}{c}10777.5 \\
0\end{array}$ & .144 & .002 & 530.70 & 607.20 & $\begin{array}{c}11120.0 \\
0\end{array}$ & .218 & .001 \\
\hline $\begin{array}{l}\text { Online } \\
\text { actions }\end{array}$ & Low & High & $\mathbf{U}$ & $\mathbf{p}$ & $\eta^{2}$ & Low & High & $\mathbf{U}$ & $\mathbf{p}$ & $\eta^{2}$ & Low & High & $\mathbf{U}$ & $\mathbf{p}$ & $\eta^{2}$ \\
\hline $\begin{array}{l}\text { Online } \\
\text { working or } \\
\text { studying }\end{array}$ & 587.01 & 593.79 & $\begin{array}{c}154418 . \\
50\end{array}$ & .746 & $<.001$ & 550.77 & 612.25 & $\begin{array}{c}139957 . \\
50\end{array}$ & .003 & .007 & 533.53 & 621.04 & $\begin{array}{c}133079 . \\
50\end{array}$ & $<.001$ & .015 \\
\hline $\begin{array}{l}\text { Art and } \\
\text { cultural online } \\
\text { activities }\end{array}$ & 577.04 & 595.09 & $\begin{array}{c}76537.0 \\
0\end{array}$ & .527 & $<.001$ & 560.07 & 702.45 & $\begin{array}{c}59573.5 \\
0\end{array}$ & $<.001$ & .022 & 570.78 & 634.66 & $\begin{array}{c}70284.5 \\
0\end{array}$ & .026 & .004 \\
\hline Buying online & 580.17 & 505.03 & 8919.50 & .342 & .001 & 578.13 & 634.22 & 9257.00 & .478 & $<.001$ & 577.47 & 675.64 & 8511.50 & .216 & .001 \\
\hline $\begin{array}{l}\text { Exterior } \\
\text { actions }\end{array}$ & Low & High & $\mathbf{U}$ & $\mathbf{p}$ & $\eta^{2}$ & Low & High & $\mathbf{U}$ & $\mathbf{p}$ & $\eta^{2}$ & Low & High & $\mathbf{U}$ & $\mathbf{p}$ & $\eta^{2}$ \\
\hline $\begin{array}{l}\text { Buying } \\
\text { outside } \\
\text { products for } \\
\text { basic needs }\end{array}$ & 323.21 & 287.00 & $\begin{array}{c}31860.5 \\
0\end{array}$ & .032 & .007 & 303.08 & 350.59 & $\begin{array}{c}30564.0 \\
0\end{array}$ & .005 & .013 & 309.29 & 330.95 & $\begin{array}{c}33529.0 \\
0\end{array}$ & .201 & .003 \\
\hline Walking dogs & 633.52 & 613.02 & $\begin{array}{c}108975 . \\
50\end{array}$ & .449 & $<.001$ & 637.20 & 595.24 & $\begin{array}{c}105135 . \\
50\end{array}$ & .121 & .002 & 627.74 & 640.90 & $\begin{array}{c}110290 . \\
00\end{array}$ & .628 & $<.001$ \\
\hline $\begin{array}{l}\text { Working } \\
\text { outside home }\end{array}$ & 630.73 & 586.32 & $\begin{array}{c}87205.5 \\
0\end{array}$ & .130 & .002 & 624.71 & 623.19 & $\begin{array}{c}93657.5 \\
0\end{array}$ & .958 & $<.001$ & 627.33 & 607.15 & $\begin{array}{c}90851.5 \\
0\end{array}$ & .492 & $<.001$ \\
\hline
\end{tabular}

Note. After the Bonferroni correction, the p value to be considered significant was .001. 


\section{Discussion}

Results obtained show that the COVID-19 pandemic is perceived as both a health and economic risk for people under confinement. However, participants' dual risk perception differs based on some aspects of their demographic profile. As might be expected, people belonging to high-risk groups due to health conditions, reported higher perceived health risk than those belonging to the general population. Similarly, employment status also appears to influence health risk perception. People working remotely from home perceived less health risk than workers who have to attend their workplace in person and those who were temporarily suspended due to quarantine. Additionally, having to leave home for work may be associated with a higher probability of exposure to the virus, which logically implies an increase in perceived health risk.

In a similar sense, perceived economic risk is linked to conditions that determine one's financial capacity, employment status in particular. People unemployed prior to, or temporarily suspended, perceived higher economic risk than participants working from home or working on site during lockdown. Economic and occupational vulnerability are therefore highlighted as a key factor linked to the perceived financial risks associated with COVID-19. Health and economic vulnerability are also related to well-being indicators during quarantine. However, it is also not possible to identify a single, integrated and stable pattern associated with well-being responses.

Two personal characteristics of participants are particularly relevant for their apparent impact on well-being indicators. First, having suffered symptoms of COVID-19 or living with symptomatic people is, as a whole, related to greater negative impact during quarantine because 
it is linked with lower positive affect and meaning in life. These results align with current international studies on the impact on stress and mental health of the population affected by COVID-19 (e.g., Bo et al., 2020; Cao et al., 2020). Second, and in the opposite direction, psychological resilience is the personal factor related with the greatest positive impact as it is linked with higher positive affect and meaning in life, and lower negative affect. Thus, psychological resilience may act as a safeguard against the psychological impact of the pandemic lockdown, as with other negative life events.

Results obtained seem to indicate that the psychological consequences of quarantine are associated not only with the individual characteristics of the person but also by their immediate social and environmental household surroundings. People who quarantined with family members did not report higher positive affect or meaning in life, but a higher negative affect than those who were alone. This may be due to a variety of causes. Being confined with other people for a prolonged period of time during quarantine, may be acting, to some extent, as a trigger for negative emotions. However, this conclusion should be interpreted with caution, more research on the matter is necessary. Following our results, the frequency of use, or lack thereof of open spaces (e.g., balconies or backyards) seems to be acting as positive environmental affordances for psychological restoration as previously found (e.g., Menatti \& Casado da Rocha, 2016).

In addition to the quarantine conditions, it is key to understand how different actions may contribute to coping with the situation. We found that most recommended coping activities were linked with positive emotional state and well-being (i.e., meaning in life and positive affect) of the quarantined people, but did not mitigate negative affect. This is the case, for example, with creative activities or maintaining daily routines. Such activities are recommended for the general population by governments and international institutions and they seem to increase positive 
affect but they did not seem to decrease negative affect in our study. A similar effect was found with other behaviors, essentially those involving seeking social contact (e.g., video calls with family and friends or community bonding actions). These behaviors were also linked with positive emotional responses but were not related with negative ones. Only one of the behaviors included in our study, exercising, had a positive significant overall effect on personal well-being, as it was associated with greater positive affect and meaning in life but also with lower negative affect. In short, caregiving behaviors, whether caring for oneself, by exercising, or for others, by altruistically helping them, seems to be at the heart of actions that result in coping with a lockdown in a more constructive manner. There is prior evidence (e.g., Prati et al., 2011) of a strong link between affective and individual behavioral responses to the threat of pandemic disease. Our findings on the connection between positive and protective behavior, and well-being are also consistent with evidence on the determinant effect of prosocial support practices, and the mediating role of positive meaningful life experiences and psychological resilience on wellbeing and mental health (e.g., Alkozei et al., 2018; Lee, 2019). In any case, it is necessary to consider that positive, health, and personal and social care behaviors affect positive affect, but do not seem to minimize negative affect.

Our research presents a series of limitations that need to be expressed. First, data collection did not follow the criteria of representativeness of any specific population. Therefore, despite having a large sample size, the results obtained must be interpreted with the necessary caution from the perspective of public health interventions. Second, data collection was carried out during the second week of lockdown when the impact associated with the initial surprise of lockdown might have been decreasing and yet the population was still unaware of the total duration of home isolation. It would be of interest to have longitudinal measures to study how 
the psychological impact developed along with the evolution of the pandemic in Spain and the duration of the lockdown. Third, our research does not identify the most serious psychological impacts of home isolation, as it does not include, for example, specific measures of anxiety or post-traumatic stress. In this regard, it is not possible to provide evidence on the long-term psychological effects that may be relevant to the future quality of life of the isolated population. Fourth. one of the aspects of this study was to analyze to what extent having suffered or currently suffering the disease, either oneself or a family member, could have a strong psychological impact. Although we were able to identify significant differences regarding both negative and positive affect, it must be noted that we were only able to access information about the presence of the disease among isolated participants in a limited, indirect, and self-reported manner. Fifth, the procedure developed for data collection may have made it difficult for people with COVID19 to respond to our instrument. Furthermore, fear of stigmatization of people with COVID-19 may have limited reporting of the disease, despite ensuring the necessary confidentiality of data treatment at all times.

In summary, with a focus on policy guidelines for future quarantines, the main evidence provided by this study relates to the relationship between positive home isolation coping activities and indicators of personal well-being. Thus, initiatives to mitigate the negative psychological impact associated with perceived risk, as well as those that specifically seek to promote the psychological and social strengths of affected individuals, should be developed. An alternative course of action would be to systematically promote positive and proactive behaviors, based, among other aspects, on self-care and helping others. Furthermore, ensuring that people under quarantine have access to environments and activities that provide opportunities for psychological restoration is important. In any case, such initiatives must respond distinctively to 
the needs of different groups of people, specially, people belonging to health risk groups, women or those economically vulnerable.

\section{References}

Alkozei, A., Smith, R., \& Killgore, W. D. (2018). Gratitude and subjective wellbeing: A proposal of two causal frameworks. Journal of Happiness Studies, 19(5), 1519-1542. https://doi.org/10.1007/s10902-017-9870-1

Aragones, J. I., Talayero, F., \& Olivos, P. (2010). Influenza A (H1N1) risk perception from" psychometric paradigm". Revista de Psicología Social, 25(3), 271-282. https://doi.org/10.1174/021347410792675633

Bo, H.-X., Li, W., Yang, Y., Wang, Y., Zhang, Q., Cheung, T., Wu, X., \& Xiang, Y.-T. (2020). Posttraumatic stress symptoms and attitude toward crisis mental health services among clinically stable patients with COVID-19 in China. Psychological Medicine, 1-2. https://doi.org/10.1017/S0033291720000999

Brooks, S. K., Webster, R. K., Smith, L. E., Woodland, L., Wessely, S., Greenberg, N., \& Rubin, G. J. (2020). The psychological impact of quarantine and how to reduce it: Rapid review of the evidence. The Lancet, 395(10227), 912-920. https://doi.org/10.1016/S0140-6736(20)30460-8

Cao, W., Fang, Z., Hou, G., Han, M., Xu, X., Dong, J., \& Zheng, J. (2020). The psychological impact of the COVID-19 epidemic on college students in China. Psychiatry Research, 287, 112934. https://doi.org/10.1016/j.psychres.2020.112934

Connor, K. M., \& Davidson, J. R. (2003). Development of a new resilience scale: The ConnorDavidson resilience scale (CD-RISC). Depression and Anxiety, 18(2), 76-82. https://doi.org/10.1002/da.10113

Cowling, B. J., Ng, D. M., Ip, D. K., Liao, Q., Lam, W. W., Wu, J. T., Lau, J. T., Griffiths, S. M., \& Fielding, R. (2010). Community psychological and behavioral responses through the first wave of the 2009 influenza A (H1N1) pandemic in Hong Kong. The Journal of Infectious Diseases, 202(6), 867-876. https://doi.org/10.1086/655811

Diener, E., \& Emmons, R. A. (1984). The independence of positive and negative affect. Journal of Personality and Social Psychology, 47(5), 1105-1117.

Fiorillo, A., \& Gorwood, P. (2020). The consequences of the COVID-19 pandemic on mental health and implications for clinical practice. European Psychiatry, 63(1), e32, 1-2. https://doi.org/10.1192/j.eurpsy.2020.35 
Flores-Kanter, P. E., \& Medrano, L. A. (2018). Comparación de dos versiones reducidas de la Escala PANAS: Análisis factoriales en una muestra argentina. Revista Iberoamericana de Diagnóstico y Evaluación-e Avaliação Psicológica, 49(4), 37-46. https://doi.org/10.21865/RIDEP49.4.03

Green, E., Chase, R. M., Zayzay, J., Finnegan, A., \& Puffer, E. S. (2018). The impact of the 2014 Ebola virus disease outbreak in Liberia on parent preferences for harsh discipline practices: A quasi-experimental, pre-post design. Global Mental Health, 5, E1. https://doi.org/10.1017/gmh.2017.24

Han, G., Zhang, J., Chu, K., \& Shen, G. (2014). Self-other differences in H1N1 flu risk perception in a global context: A comparative study between the United States and China. Health Communication, 29(2), 109-123. https://doi.org/10.1080/10410236.2012.723267

Instituto de Salud Carlos III. (n.d.). Retrieved April 25, 2020, from https://covid19.isciii.es

KO, C.-H., YEN, C.-F., YEN, J.-Y., \& YANG, M.-J. (2006). Psychosocial impact among the public of the severe acute respiratory syndrome epidemic in Taiwan. Psychiatry and Clinical Neurosciences, 60(4), 397-403. https://doi.org/10.1111/j.1440-1819.2006.01522.x

Lee, M. A. (2019). Volunteering and happiness: Examining the differential effects of volunteering types according to household income. Journal of Happiness Studies, 20(3), 795-814. https://doi.org/10.1007/s10902-018-9968-0

Lee, J., Blackmon, B. J., Cochran, D. M., Kar, B., Rehner, T. A., \& Gunnell, M. S. (2018). Community resilience, psychological resilience, and depressive symptoms: An examination of the Mississippi Gulf Coast 10 years after Hurricane Katrina and 5 years after the Deepwater Horizon oil spill. Disaster Medicine and Public Health Preparedness, 12(2), 241-248. https://doi.org/10.1017/dmp.2017.61

Li, S., Wang, Y., Xue, J., Zhao, N., \& Zhu, T. (2020). The impact of COVID-19 epidemic declaration on psychological consequences: A study on active Weibo users. International Journal of Environmental Research and Public Health, 17(6), 2032. https://doi.org/10.3390/ijerph17062032

Liu, X., Kakade, M., Fuller, C. J., Fan, B., Fang, Y., Kong, J., Zhiqiang, G., \& Wu, P. (2012). Depression after exposure to stressful events: Lessons learned from the severe acute respiratory syndrome epidemic. Comprehensive Psychiatry, 53(1), 15-23. https://doi.org/10.1016/j.comppsych.2011.02.003

Lohiniva, A.-L., Sane, J., Sibenberg, K., Puumalainen, T., \& Salminen, M. (2020). Understanding coronavirus disease (COVID-19) risk perceptions among the public to enhance risk communication efforts: A practical approach for outbreaks, Finland, February 2020. Eurosurveillance, 25(13), 2000317. https://doi.org/10.2807/1560-7917.ES.2020.25.13.2000317

McCloskey, B., \& Heymann, D. L. (2020). SARS to novel coronavirus-old lessons and new lessons. Epidemiology \& Infection, 148, e22, 1-4. https://doi.org/10.1017/S0950268820000254

Menatti, L., \& Casado da Rocha, A. (2016). Landscape and health: Connecting psychology, aesthetics, and philosophy through the concept of affordance. Frontiers in Psychology, 7, 571. https://doi.org/10.3389/fpsyg.2016.00571 
Mihashi, M., Otsubo, Y., Yinjuan, X., Nagatomi, K., Hoshiko, M., \& Ishitake, T. (2009). Predictive factors of psychological disorder development during recovery following SARS outbreak. Health Psychology, 28(1), 91-100. https://doi.org/10.1037/a0013674

Moore, P. J., Chrabaszcz, J. S., Peterson, R. A., Rohrbeck, C. A., Roemer, E. C., \& Mercurio, A. E. (2014). Psychological resilience: The impact of affectivity and coping on state anxiety and positive emotions during and after the Washington, DC sniper killings. Anxiety, Stress \& Coping, 27(2), 138-155. https://dx.doi.org/10.1080/10615806.2013.828202

Morgan, J., \& Farsides, T. (2009). Psychometric evaluation of the meaningful life measure. Journal of Happiness Studies, 10(3), 351-366. https://doi.org/10.1007/s10902-008-9093-6

Morgan, J., \& Robinson, O. (2013). Intrinsic aspirations and personal meaning across adulthood: Conceptual interrelations and age/sex differences. Developmental Psychology, 49(5), 999-1010. https://doi.org/10.1037/a0029237

Notario-Pacheco, B., Solera-Martínez, M., Serrano-Parra, M. D., Bartolomé-Gutiérrez, R., GarcíaCampayo, J., \& Martínez-Vizcaíno, V. (2011). Reliability and validity of the Spanish version of the 10-item Connor-Davidson Resilience Scale (10-item CD-RISC) in young adults. Health and Quality of Life Outcomes, 9(1), 63. https://doi.org/10.1186/1477-7525-9-63

Osofsky, H. J., Osofsky, J. D., \& Hansel, T. C. (2011). Deepwater horizon oil spill: Mental health effects on residents in heavily affected areas. Disaster Med Public Health Prep, 5(4), 280-286. https://doi.org/10.1001/dmp.2011.85

Paul, F. J., Mandal, M. K., Ramachandran, K., \& Panwar, M. R. (2010). Interpersonal behavior in an isolated and confined environment. Environment and Behavior, 42(5), 707-717. https://doi.org/10.1177/0013916509336889

Peng, E. Y.-C., Lee, M.-B., Tsai, S.-T., Yang, C.-C., Morisky, D. E., Tsai, L.-T., Weng, Y.-L., \& Lyu, S.-Y. (2010). Population-based post-crisis psychological distress: An example from the SARS outbreak in Taiwan. Journal of the Formosan Medical Association, 109(7), 524-532. https://doi.org/10.1016/S0929-6646(10)60087-3

Prati, G., Pietrantoni, L., \& Zani, B. (2011). A social-cognitive model of pandemic influenza H1N1 risk perception and recommended behaviors in Italy. Risk Analysis: An International Journal, 31(4), 645-656. https://doi.org/10.1111/j.1539-6924.2010.01529.x

Real Decreto 463/2020, de 14 de marzo, por el que se declara el estado de alarma para la gestión de la situación de crisis sanitaria ocasionada por el COVID-19. BOE, 67, de 14 de marzo de 2020, 25390-25400. Retrieved March 18, 2020, from https://www.boe.es/diario_boe/txt.php?id=BOE$\underline{\mathrm{A}-2020-3692}$

Sandal, G. M., van deVijver, F. J., \& Smith, N. (2018). Psychological hibernation in Antarctica. Frontiers in Psychology, 9, 2235. https://doi.org/10.3389/fpsyg.2018.02235

Shin, L., Ruberton, P., \& Lyubomirsky, S. (2018). The Spotlight activity: Development and feasibility test of a naturalistic attention-redirection well-being intervention. Journal of Positive School Psychology, 2(1), 64-91. 
Slovic, P., Fischhoff, B., \& Lichtenstein, S. (1985). Characterizing perceived risk. In R. W. Kates, C. Hohenemser \& J. X. Kasperson (Eds.), Perilous progress: Managing the hazards of technology (pp. 91-125). Westview. https://ssrn.com/abstract=2185557

van den Bosch, M., \& Sang, ̊. O. (2017). Urban natural environments as nature-based solutions for improved public health-A systematic review of reviews. Environmental Research, 158, 373-384. https://dx.doi.org/10.1016/j.envres.2017.05.040

Wang, C., Pan, R., Wan, X., Tan, Y., Xu, L., Ho, C. S., \& Ho, R. C. (2020). Immediate psychological responses and associated factors during the initial stage of the 2019 coronavirus disease (COVID-19) epidemic among the general population in China. International Journal of Environmental Research and Public Health, 17(5), 1729. https://doi.org/10.3390/ijerph17051729

Watson, D., Clark, L. A., \& Tellegen, A. (1988). Development and validation of brief measures of positive and negative affect: the PANAS scales. Journal of Personality and Social Psychology, 54(6), 1063-1070.

Weber, J., Javelle, F., Klein, T., Foitschik, T., Crucian, B., Schneider, S., \& Abeln, V. (2019). Neurophysiological, neuropsychological, and cognitive effects of 30 days of isolation. Experimental Brain Research, 237(6), 1563-1573. https://doi.org/10.1007/s00221-019-05531-0

WHO/Europe (2020). Retrieved April 20, 2020, from https://www.euro.who.int/en/home

World Health Organization - WHO (2020a). WHO Director-General's opening remarks at the media briefing on COVID-19 - 11 March 2020. Retrieved March 16, 2020, from https://www.who.int/es/dg/speeches/detail/who-director-general-s-opening-remarks-at-themedia-briefing-on-covid-19---11-march-2020

World Health Organization - WHO (2020b). Coronavirus disease (COVID-19) advice for the public. Retrieved March 20, 2020, from https://www.who.int/es/emergencies/diseases/novelcoronavirus-2019/advice-for-public

World Health Organization - WHO (2020c). Coping with stress during the 2019-nCoV outbreak. Retrieved March 20, 2020, from https://www.who.int/docs/default-source/coronaviruse/200762coping-with-stress-during-the-2019-sp.pdf 